\title{
GOVERNANÇA GLOBAL E A AGENDA DO TRABALHO DECENTE DA ORGANIZAÇÃO INTERNACIONAL DO TRABALHO: IMPLICAÇÕES NA REFORMA TRABALHISTA DO BRASIL.
}

\author{
GLOBAL GOVERNANCE AND THE DECENT WORK AGENDA OF \\ THE INTERNATIONAL LABOR ORGANIZATION: IMPLICATIONS \\ FOR BRAZIL'S LABOR REFORM.
}

\section{GOBERNANZA GLOBAL Y LA AGENDA DEL TRABAJO DECENTE DE LA ORGANIZACIÓN INTERNACIONAL DEL TRABAJO: IMPLICACIONES EN LA REFORMA LABORAL DE BRASIL.}

\author{
JOSE ALBERTO ANTUNES DE MIRANDA* \\ Universidade La Salle, Canoas, Brasil \\ FERNANDA COLOMBY ORTIZ** \\ Universidade do estado do Rio Grande do Sul, UERS, Brasil
}

\begin{abstract}
Resumo: Esse artigo se propõe a realizar uma análise de pontos críticos da Reforma Trabalhista no Brasil a partir das recomendações emitidas pela Organização Internacional do Trabalho através do documento denominado «Agenda do Trabalho Decente» no qual a OIT estabelece objetivos principais e estratégicos, acerca de princípios e direitos fundamentais no trabalho. A metodologia utilizada é a fenomenológica, constatando os fatos para, a partir dos mesmos, tecer possibilidades explicativas com potencial de fornecer um quadro compreensivo da realidade que se tenta abranger. É realizada a revisão bibliográfica explorando o marco teórico de Niklas Luhmann. Conclui-se que o novo modelo legislativo não observa as questões sociais que permeiam as relações trabalhistas, principalmente aquelas relativas à proteção do
\end{abstract}

\footnotetext{
* Possui graduação em Direito pela Universidade do Vale do Rio dos Sinos (1996), Especialização em Integração e Mercosul pela UFRGS (1999), Mestrado em Relações Internacionais pela Universidade Federal do Rio Grande do Sul (2004) e Doutorado em Estudos Estratégicos Internacionais pela UFRGS (2012). Atualmente é Assessor de Assuntos Interinstitucionais e Internacionais e professor permanente do Mestrado em Direito e Sociedade além de integrar o corpo docente do Curso de Relações Internacionais da Universidade La Salle. Tem experiência na área de Relações Internacionais, com ênfase em Política Externa e Análise da Política Externa, Integração Regional, Organizações Internacionais, Direito Internacional, Constituição e Relações Exteriores e Internacionalização da Educação Superior. E-mail: jose.miranda@unilasalle.edu.br

${ }^{* *}$ Mestranda em Direito, da Universidade La Salle - Unilasalle, formada em Direito pela Pontifícia Universidade Católica do Rio Grande do Sul - PUCRS, Especialista em Direito do Trabalho e Processo do Trabalho pela LFG. Este trabajo fue recibido el 07 de agosto de 2018 y aprobado el 11 de octubre de 2018.
} 
trabalho da mulher, proteção do menor, promoção do emprego de qualidade e extensão da proteção social, conforme previsto nas recomendações estabelecidas pela OIT.

Palavras-chave: Agenda de Trabalho Decente; Reforma Trabalhista; Direitos Fundamentais; Organização Internacional do Trabalho; Princípio da Proteção ao Trabalhador.

\begin{abstract}
This article proposes an analysis of critical points of the Brazilian Labor Reform based on the recommendations issued by the International Labor Organization through the document entitled «Decent Work Agenda», in which the ILO establishes main and strategic objectives on principles and fundamental rights at work. The methodology used is the phenomenological one, stating the facts to, from the same, to weave explanatory possibilities with the potential to provide a comprehensive picture of the reality that is tried to cover. A bibliographic review is carried out exploring the theoretical framework of Niklas Luhmann. It is concluded that the new legislative model does not observe the social issues that permeate the labor relations, as foreseen in the recommendations established by the ILO.
\end{abstract}

Keywords: Decent Work Agenda; Labor Reform; Fundamental Rights; International Labor Organization; Principle of Worker Protection.

Resumen: Este artículo se propone realizar un análisis de puntos críticos de la Reforma Laboral en Brasil a partir de las recomendaciones emitidas por la Organización Internacional del Trabajo a través del documento denominado «Agenda del Trabajo Decente» en el que la OIT establece objetivos principales y estratégicos, principios y derechos fundamentales en el trabajo. La metodología utilizada fue la fenomenológica, a partir de la misma, un potencial de posibilidades explicativas con potencial de fornecer un cuadro comprehensivo da realidad que se trató de reorganizar. Para el análisis del tema, se adoptó la revisión bibliográfica como metodología de investigación, explorando el marco teórico en Niklas Luhmann. Se concluye que el nuevo modelo legislativo no observa las cuestiones sociales que permean las relaciones laborales, conforme a lo previsto en las recomendaciones establecidas por la OIT.

Palabras clave: Agenda de Trabajo Decente; Reforma Laboral; Derechos Fundamentales; Organización Internacional del Trabajo; Principio de Protección al Trabajador.

\title{
Introdução
}

O papel da Organização Internacional do Trabalho na condução de um processo reflexivo que permita a aplicação no Direito Trabalhista das Convenções e recomendações da OIT, possibilita uma análise ante a possibilidade de um Direito do Trabalho em âmbito global. Esse direito não se limita ao Direito Internacional do Trabalho, mas avança, principalmente com relação aos Direitos Humanos, a partir das recomendações da Agenda do Trabalho Decente em contraste com as principais alterações apresentadas na Reforma Trabalhista realizada no Brasil.

$\mathrm{Na}$ primeira seção desse artigo se estabelece um panorama sobre o papel de governança da Organização Internacional do Trabalho realizando uma contextualização mundial dos processos de reformas trabalhistas em diversos países da Europa e da América Latina. Essas reformas foram realizadas com o intuito de flexibilizar as normas da legislação laboral e sob o pretexto de reduzir o déficit empregatício ocasionado pela crise econômica mundial.

$\mathrm{Na}$ segunda seção optou-se por explorar a Agenda do Trabalho Decente da Organização Internacional do Trabalho em conjunto com o Plano Nacional de Trabalho Decente. Em 1999 a Organização Internacional do Trabalho firmou o conceito de trabalho 
decente, que sintetiza a sua missão histórica de promover oportunidades para que homens e mulheres obtenham um trabalho produtivo e de qualidade, com condições mínimas de igualdade, dignidade humana, segurança e liberdade. O trabalho decente é considerado condição fundamental para a superação da pobreza, a redução das desigualdades sociais, a garantia da governabilidade democrática e o desenvolvimento sustentável.

Se identificam pontos críticos trazidos pela reforma trabalhista do Brasil, em contraste com as recomendações da Organização Internacional do Trabalho a partir de uma avaliação acerca do posicionamento da OIT, das razões por que há dificuldade na aplicação das Convenções e recomendações da Organização por parte dos Estados-Membros e sobre as tendências reflexivas no direito transnacional.

\section{O movimento de reformas trabalhistas no mundo: problemas comuns no contexto da governança da OIT;}

A onda de reformas trabalhistas teve início na Europa, onde enfrentou resistência relevante de movimentos sociais e da população em geral, se estendendo posteriormente para países da América Latina, sustentando que a imprescindibilidade de flexibilização e modernização se devia à necessidade de melhorar as condições para a geração de empregos, reduzindo assim, os índices de desemprego

A globalização culminou no aumento das complexidades do mundo contemporâneo, permeando o equilíbrio e a organização das decisões no âmbito da governança mundial em seus mais variados perímetros de decisões. Uma sociedade planetária e aberta, culminando no enfraquecimento da soberania nacional, diante das instâncias superiores e inferiores, em nível global, ditam a «velocidade» da força econômica, como é o caso do valor ou peso da moeda que muda, conforme o mercado (Miranda, Fraga, 2017).

Este desenvolvimento de mercados de capitais se vincula além das nações, pois estariam dentro dos modelos de produção, movimentando o deslocamento da atividade econômica, de um país a outro, o que contribui para uma emergência de uma nova divisão internacional do trabalho, iniciada na década de 30 e $40 .^{1}$

A substituição do indivíduo pelo mercado visualiza uma inversão de valores na regulação social. Esta inversão no contexto global influenciou uma tendência generalizada à democratização como uma «bandeira» de justificação para a transformação do mercado (Arnaud, 2005). O reconhecimento dos direitos sociais torna-se amplo e complexo, pois fortalece universalmente os direitos humanos e o respeito ao princípio da igualdade, direito ao trabalho, saúde e a seguridade social, além de ser necessário salvaguardar direitos das minorias (González, 2013).

A América Latina não ficou imune a todas essas mudanças e é impactada pela expansão do processo assim como pelo seu recuo. A reconfiguração dos espaços globais e regionais tem o marco das transformações ocorridas no sistema internacional e o subsistema latino-americano. No século XXI, há uma nova ordem global emergente, onde a transição geral das condições para esta nova etapa é caracterizada pela heterogeneidade.

A América Latina convive já há muito tempo com a preponderância de uma classe capitalista transnacional, que influencia o processo de globalização na região, destacando as multinacionais e a elite local, o que não conseguiu contribuir para a diminuição de décadas de desigualdades.

\footnotetext{
${ }^{1} \mathrm{O}$ processo de internacionalização da economia, iniciado na Segunda Guerra Mundial, proporcionou um crescimento do comércio e investimentos internacionais com uma velocidade superior à produção conjunta dos países, elevando a condição humana de existência (Vieira, 1997).
} 
O cenário em que se dá a aplicação das políticas de globalização neoliberal amplia a situação no continente, eis que séculos de colonização e desigualdades, representam o cenário propício para experimentos como privatizações, regulações, supressão de direitos trabalhistas, situações que caracterizaram uma América Latina, a contar da década de 1990, em situação de dependência frente ao mundo, que permanece nos dias atuais (Miranda, Moises, 2017).

Os estudos conduzidos pelo Centro de Estudos Sindicais e de Economia do Trabalho, da Universidade de Campinas, indicam que essas reformas vêm falhando sistematicamente em seus alegados objetivos, após a coleta de dados sobre o período que se seguiu às Reformas, não houve evidências de que a flexibilização de fato resulte em aumento nos níveis de ocupação e em menores taxas de desemprego. ${ }^{2}$

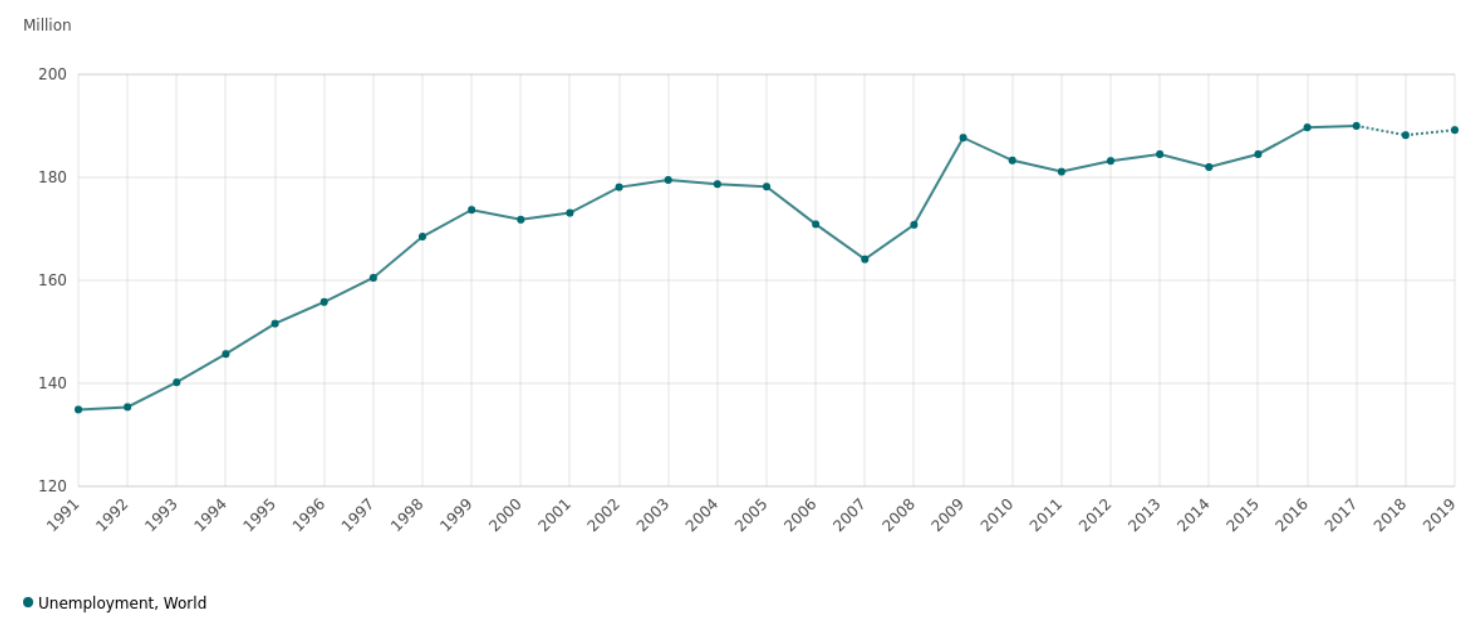

Por outro lado, a redução da teia de proteção legal ao trabalhador resulta em aumento de situações de emprego precárias, aumento da desigualdade social e em um agravamento da segmentação no mercado de trabalho. Na Alemanha as reformas trabalhistas realizadas no ano 2000, aumentaram a inclinação dos desempregados a aceitar qualquer tipo de oferta de emprego, sem restrições à ocupação, qualificação ou salários, os benefícios sociais foram reduzidos e foram estabelecidas importantes restrições à aposentadoria.

Dos postos de trabalho criados entre 2000 e 2015, naquele país, mais de $60 \%$ (sessenta por cento) eram de contratos temporários, contratos de prazo fixo, pequenos serviços ou trabalho em regime de tempo parcial (meio período). As reformas tiveram um papel fundamental em agravar a tendência de crescimento dos contratos atípicos. ${ }^{4}$

Ainda assim, a diferença social, política, econômica e cultural, entre o Brasil e a Alemanha é imensa e portanto, não se pode deixar de considerar questões pertinentes, como por exemplo, o fator social, na Alemanha a sociedade tem acesso à educação, saúde e à

\footnotetext{
${ }^{2}$ Experiências Internacionais em Reforma Trabalhista - Centro de Estudos Sindicais e de Economia do Trabalho -UNICAMP: «Goo.Gl/Tkrpau».

${ }^{3}$ Dados do desemprego mundial da Organização Internacional do Trabalho, no período de 1991 até 2017, com relação ao período de 2018 até 2019, esses dados são uma projeção. Disponível em: «goo.gl/J45seV».

${ }^{4}$ Centre for Policy Studies «Goo.Gl/8o4zgz».
} 
habitação por custos irrisórios, além de acesso à formação profissional de qualidade, já em um país como o Brasil, de políticas sociais nulas ou inefetivas o efeito dessa precarização tende a ser nocivo aos trabalhadores, justamente o elo mais fraco dessa corrente. ${ }^{5}$

Segundo Luhmann, um dos pontos de distinção do desenvolvimento europeu no mundo, se deve à acentuação das premissas legais da convivência social:

«Uma das particularidades que distingue o desenvolvimento europeu no mundo, se deve sem dúvida à marcada acentuação das premissas legais da convivência social. Essa convivência se verificou sob o fundamento do Direito Civil romano e sob a formação de princípios sustentados no direito natural» (Luhmann, 2005: 474).

A relevante desigualdade social, se traduz em um considerável problema para o Brasil, influenciando diretamente outras questões de ordem política e social, conforme Alexandre César:

«Sendo o Brasil um dos primeiros países no ranking mundial de pior distribuição de renda (assustadores índices atestam que os 10\% mais ricos "abocanham" quase 50\% da renda nacional), não existe nenhuma dificuldade em visualizar o quão limitador ao efetivo acesso à justiça é a desigualdade econômica» (César, 2002: 92).

Uma das consequências dessa significativa desigualdade social é a obstaculização do acesso aos direitos básicos, o que impede ou dificulta de forma substancial, o exercício da cidadania, o impedimento ao trabalhador para acessar o judiciário é muitas vezes, de ordem econômica, o Estado, por sua vez, quando não estende aos hipossuficientes a garantia de acesso à justiça, está em flagrante descompasso em relação às normas Constitucionais. Conforme indica José Renato Nalini:

«A barreira da pobreza impede a submissão de todos os conflitos à apreciação de um juiz imparcial. Mas é verdadeiramente trágica se considerada a dimensão do acesso do pobre aos direitos. Os despossuídos são privados até dos direitos fundamentais de primeira geração, para eles meras declarações retóricas, sem repercussão em sua vida prática» (Nalini, 1997).

Assim, a adesão do Brasil à Agenda do Trabalho Decente e o estabelecimento de um Plano Nacional do Trabalho Decente, denotam medidas necessárias que visam o restabelecimento de uma postura que priorize os aspectos humanos e sociais concernentes ao trabalho.

O papel do Estado no cenário mundial sofreu o impacto de todas essas experiências, aprofundando a necessidade de sua readequação a partir do sistema de governança global. A pouca consistência dos governos nacionais e sua incapacidade para adaptar-se às mudanças visando satisfazer às novas necessidades organizativas e também proporcionar um sistema de proteção social - cuja implantação nem sempre é uma demanda do processo de globalização implica na necessidade de participação comunitária que busque respostas satisfatórias por meio de outras formas de representação democrática.

\footnotetext{
${ }^{5}$ Julimar Bichara «goo.gl/kuiwbp».
} 


\section{A Agenda do Trabalho Decente da Organização Internacional do Trabalho no âmbito de sua governança global}

A fundação da Organização Internacional do Trabalho (OIT) ocorreu em 1919 com o objetivo de promover a justiça social, tendo sido ganhadora do Prêmio Nobel da Paz em 1969, é a única agência das Nações Unidas que tem estrutura tripartite, na qual representantes de governos, de organizações de empregadores e de trabalhadores de 183 Estados-membros participam em situação de igualdade das diversas instâncias da Organização. (ILO, 2015)

Frente aos desafios da globalização e aos déficits das políticas em matéria de crescimento e emprego, em 1999 a OIT instituiu o Trabalho Decente como o objetivo central de todas as suas políticas e programas. A noção de Trabalho Decente abrange a promoção de oportunidades para mulheres e homens do mundo para conseguir um trabalho produtivo, adequadamente remunerado, exercido em condições de liberdade, equidade e segurança e capaz de garantir uma vida digna.

Não há um governo mundial acima dos Estados soberanos. No entanto há interesses, regras, instituições e organizações comuns criados pelos Estados para ajudar a constituir a interação entre eles. Hedley Bull cunhou a expressão sociedade anárquica: há uma ordem social mundial composta por Estados independentes. (BULL, 2002)

A governança global e sua concepção teórica como a expressa por James Rosenau, utiliza o termo governança global no sentido de enfatizar as implicações de uma orientação e reorientação generalizada das habilidades e dos horizontes políticos das pessoas. Os padrões de mudança da ordem global estão relacionados com as mudanças na vida global. Rosenau descreveu a implicação de novas aptidões e horizontes políticos como tendendo a um mundo bifurcado, composto de reinos centrais e multicêntricos. $\mathrm{O}$ autor sugeriu que esse fenômeno implicaria em uma proliferação em muitas direções simultâneas: a subnacional, a transnacional e global (Rosenau, 2000).

Ao longo dos últimos trinta anos a governança se intensificou e se afastou do contexto restrito dos governos nacionais e passou a ser uma governança de múltiplos níveis. Os participantes não são simplesmente governos e organizações internacionais tradicionais, mas também organizações não governamentais e outros atores não-estatais. Uma parte da governança de múltiplos níveis reflete uma cooperação convencional mais intensa entre Estados independentes e parte dela representa uma transformação mais profunda em direção ao que se preconizava governança supranacional. A condição moderna do Estado seria transformada de modo significativo (Goncalves \& Costa, 2011).

José Miranda e Wanda Capeller salientam que atualmente se vive um processo onde os discursos se radicalizam em extremos gerando a sensação de volta ao status quo anterior onde o Estado volta a assumir a sua razão de ser, desprestigiando o processo de governança global, que é uma evolução das normas de convívio no mundo. O processo de governança global ainda que se apresente de uma forma deficitária em seu aspecto democrático contribui para a formação de um pensamento de justiça, interesse comum e progresso da humanidade (Miranda, Capeller, 2017).

Ainda segundo esses autores é importante se ter em mente que o direito não é o único curso de ação das relações internacionais, mas também não podemos negligenciar o direito internacional. Muitas vezes as abordagens realistas contribuem para a marginalização do direito nos estudos políticos internacionais. $\mathrm{O}$ argumento apresentado é que o direito não tem força coercitiva o que não permite a sua eficácia (Miranda, Capeller, 2017).

A atividade normativa internacional obteve um considerável avanço desde o século XIX. Houve o aumento de sua diversificação, como o desenvolvimento de atos negociados 
não convencionais e do direito que atende às organizações internacionais, ao aumento das áreas de aplicação, como o direito material até a expansão dos atores de sua elaboração. $\mathrm{O}$ direito internacional oferece um quadro formal a este arranjo de interesses. Nesse sentido, ele é organizador, definindo campos de negociação, fixando os compromissos subscritos e designando, embora sem poder sancioná-los sempre, os comportamentos de desvio. Essa tarefa é habitualmente considerada como reguladora, o que pode gerar confusão, na medida em que a regulação em questão define mais uma ordem e busca menos equilíbrio (Devin, 2009: 149-159).

A produção normativa no âmbito mundial deve satisfazer a busca pelo consenso. Nas negociações multilaterais, como exemplo as que defendem os considerados bem públicos globais como o meio ambiente, saúde, paz, cuja lista as vezes é imprecisa quanto ao próprio conceito, pois os atores e interesses são muitos, tornando o exercício particularmente complexo.

Atingir consensos no âmbito global não é uma forma fácil em um contexto atual de interesses diversos dos Estados e do aumento dos discursos excludentes e de extremos. Mas as práticas de governança já possuem um impacto muito forte no âmbito do sistema e da sociedade internacional até para os mais excluídos desse sistema. Decisões no âmbito daquilo que se chama de bens públicos globais são na pratica contemporânea do direito e da política, já parte do sistema de governança ainda que em muitos momentos um pouco frágeis (Miranda, Capeller, 2017).

Quadro 1 - Trabalho Decente - eixo central para onde convergem os quatro objetivos estratégicos da OIT

1) Respeito às normas internacionais do trabalho, em especial aos princípios e direitos fundamentais do trabalho;

2) Promoção do emprego de qualidade;

3) Extensão da proteção social;

4) Fortalecimento do diálogo social;

Fonte: Autoria própria a partir dos objetivos estratégicos da OIT previsto no documento: Plano Nacional do Trabalho Decente - PNTD, ILO, 2010.

Além da promoção permanente das normas internacionais do trabalho, do emprego da melhoria das condições de trabalho e da ampliação da proteção social, a atuação da OIT no Brasil tem se caracterizado pelo apoio ao esforço nacional de promoção do trabalho decente em áreas como o combate ao trabalho forçado, ao trabalho infantil e ao tráfico de pessoas para fins de exploração sexual e comercial, a promoção da igualdade de oportunidades e tratamento para todas as pessoas no trabalho e a promoção de trabalho decente para os jovens, dentre outras formas de atuação.

O Plano Nacional de Trabalho Decente tem por finalidade principal contribuir para a promoção do Trabalho Decente no Brasil conforme compromissos assumidos pelo País na Agenda Nacional do Trabalho Decente - ANTD. 
Quadro 2 - Compromissos assumidos na Agenda de Trabalho Decente

1) Impulsionar o desenvolvimento sustentável e a inclusão social através da promoção
do trabalho decente;
$\begin{aligned} & \text { 2) A geração de mais e melhores empregos, com igualdade de oportunidades e de } \\ & \text { tratamento; }\end{aligned}$

3) A erradicação do trabalho escravo e do trabalho infantil em especial em suas piores formas;

4) Fortalecimento dos atores tripartites e do diálogo social como um instrumento de governabilidade democrática;

Fonte: Autoria própria a partir dos compromissos elencados na Agenda Nacional do Trabalho Decente previsto no documento - PNTD, ILO, 2010.

A sua implementação visa fortalecer a capacidade do Estado brasileiro para avançar no enfrentamento dos principais problemas estruturais da sociedade e do mercado de trabalho, entre os quais se destacam: a pobreza e a desigualdade social; o desemprego e a informalidade; a extensão da cobertura da proteção social; a parcela de trabalhadoras e trabalhadores sujeitos a baixos níveis de rendimentos e produtividade; os elevados índices de rotatividade no emprego; as desigualdades de gênero e raça/etnia; as condições de segurança e saúde nos locais de trabalho, sobretudo na zona rural.

O Plano Nacional de Trabalho Decente foi construído por meio de trabalho participativo realizado pelo Grupo de Trabalho Interministerial - GTI composto por representantes dos Ministérios e Secretarias Especiais que integram o Comitê Executivo Interministerial e em consulta com os atores sociais, por meio de Grupo de Trabalho Tripartite - GTT, integrado por representantes do governo, dos trabalhadores e dos empregadores (IPEA, 2010).

Criado pelo Ministério do Trabalho e Emprego - MTE, em novembro de 2007, o Grupo de Trabalho Tripartite - GTT, tem a finalidade de assessorar o Comitê Executivo Interministerial - CEI, no processo de implementação da Agenda Nacional de Trabalho Decente - ANTD. (ILO, 2010 - PNTD)

Os principais compromissos do Brasil na promoção da ANTD e da Agenda Hemisférica do Trabalho Decente são em relação aos seguintes temas: geração de empregos; recuperação progressiva do valor real do salário mínimo; combate ao trabalho forçado e ao trabalho infantil; extensão da proteção social, especialmente a mulheres, jovens, populações negras e populações indígenas e construção de mecanismos voltados para a promoção da igualdade de gênero. (ILO, 2010 - PNTD)

Assim, o Plano Nacional de Trabalho Decente constitui o instrumento adequado para a implementação do compromisso firmado entre o Governo brasileiro e a OIT expresso na Agenda Nacional de Trabalho Decente, estabelecendo as prioridades, os resultados esperados e as estratégias, metas, prazos, produtos e indicadores de avaliação. Esse plano deverá ser monitorado e periodicamente avaliado com suporte da OIT e em consulta às organizações de empregadores e de trabalhadores.

A cooperação técnica é um dos principais mecanismos de implementação do Plano, constituindo, assim, o marco da cooperação entre as partes, os projetos e atividades de cooperação técnica que já vêm sendo desenvolvidos pela OIT no Brasil, assim como os que poderão vir a ser negociados e aprovados, são instrumentos importantes para a consecução 
dos resultados esperados. O Governo brasileiro e a OIT firmaram compromisso de envidar esforços para mobilizar, nacional e internacionalmente, os recursos técnicos e financeiros necessários à execução das ações definidas no Plano. (ILO, 2010 - PNTD)

O Plano também incorpora, como parte de seus objetivos, a promoção da Cooperação Internacional em matéria de Trabalho, Emprego e Proteção Social, com ênfase na Cooperação Sul-Sul, tal como previsto no Acordo de Cooperação firmado em 29 de julho de 1987, entre a OIT e o Governo brasileiro para a Cooperação Técnica em Outros Países da América Latina e Países da África (Abramo, 2015).

Com base no texto desse acordo, é possível identificar que a OIT e o Brasil promoverão a difusão e o intercâmbio com outros países, em especial os países em desenvolvimento, de boas práticas e iniciativas desenvolvidas no Brasil acerca dos temas que conformam esta agenda (ILO, 2003).

Um dos grandes desafios a ser enfrentado na perspectiva de um modelo de crescimento e desenvolvimento inclusivo e sustentável é garantir que o emprego seja tratado como elemento central das políticas públicas. Para tal, se observa que há necessidade do desenvolvimento de condições técnicas necessárias para que o emprego possa ser incorporado como um objetivo da política econômica. Entretanto, em uma escalada neoliberal, seguindo a tendência dos países europeus, a Reforma Trabalhista adotada no Brasil, vem em sentido contrário às recomendações da ANTD da Organização Internacional do Trabalho (ILO, 2003).

É importante salientar que as instituições internacionais, como por exemplo a OIT ganharam muita importância ao longo dos últimos anos, mas também há críticas constantes ante o problema do déficit democrático e de representatividade. Muitas dessas instituições atuam de forma muito distante do cidadão comum. Apesar disso, elas possuem hoje uma importância muito grande diante do conjunto de demandas do sistema internacional. Os Estados veem-se impotentes para dar conta de muitas dessas demandas.

As instituições multilaterais facilitam a cooperação internacional e influenciam o comportamento dos Estados a partir da constituição da agenda, o monitoramento da compliance (conformidade às regras) e outras funções. Mesmo em condições de anarquia os Estados irão frequentemente se engajar em comportamentos de cooperação facilitado pelas instituições internacionais que reduzem as inseguranças (Miranda, Cademartori, 2018).

A proliferação de organizações internacionais durante o último século marcou a transformação da velha ordem internacional em uma nova ordem mundial, centrada no sistema das Nações Unidas; contudo, as fontes fundamentais da ordem internacional - a guerra, a balança de poder, o papel das grandes potências, o Direito Internacional e a diplomacia tradicional - continuaram a funcionar. Se por um lado entramos em uma nova ordem, assente sobretudo no papel das Nações Unidas, por outro vigoram ainda as principais premissas do realismo, mesmo em termos de ONU. Embora estejam bem presentes princípios que tendem a valorizar a paz e a segurança, a agenda tradicional, a agenda das Nações Unidas, abrange muitas outras áreas de preocupação, como economia, cultura, finanças ou social. (Muldoon, 2007)

O fortalecimento da sociedade civil transnacional é mais um fator que indica que o poder estatal não satisfaz sozinho os anseios da humanidade. Surge assim a necessidade de operar com novas categorias, sendo uma das principais as instituições internacionais. 


\section{A Reforma Trabalhista no Brasil em contraste com os objetivos da Agenda do Trabalho Decente da Organização Internacional do Trabalho}

Após decorridos cerca de dois séculos de incessantes esforços, no sentido de consolidar as legislações sociais trabalhistas, é possível observar que a lógica mundial vem sofrendo alterações, a normatização que envolve o mundo do trabalho vem perdendo o reflexo dos fatores originários que demandaram sua evolução, para dar lugar a um fenômeno internacionalizante inverso, que não vem buscando resguardar os interesses e a melhoria das condições de vida da classe operária, mas sim os interesses do capital internacional, fator dominante nos mercados mundiais, e assim, pressionando os países em nome da competitividade, a um retrocesso na legislação trabalhista - que a muito custo adotou um viés mais protetivo - a voltar para os moldes liberais de outrora.

A Reforma Trabalhista realizada no Brasil em 2017, trouxe importantes alterações ao texto (até então vigente) da Consolidação das Leis Trabalhistas, a partir dessas alterações se operaram mudanças significativas com relação à posição do Brasil, frente às recomendações e compromissos firmados junto à OIT, por meio da ANTD, considerando que dentre as mudanças estabelecidas pela legislação, está o disposto nos seguintes artigos da Lei $13.467 / 2017 .^{6}$

«Art. 394-A. A empregada gestante ou lactante somente poderá trabalhar em ambiente insalubre mediante a apresentação de atestado médico que comprove que o ambiente não afetará a saúde ou oferecerá algum risco à gestação ou à lactação.

Art. 442-B. A contratação do autônomo, cumpridas por este todas as formalidades legais, com ou sem exclusividade, de forma contínua ou não, afasta a qualidade de empregado prevista no art. $3^{\circ}$ desta Consolidação.

Art. 443. O contrato individual de trabalho poderá ser acordado tácita ou expressamente, verbalmente ou por escrito, por prazo determinado ou indeterminado, ou para prestação de trabalho intermitente.

$\S 3^{\circ}$ Considera-se como intermitente o contrato de trabalho no qual a prestação de serviços, com subordinação, não é contínua, ocorrendo com alternância de períodos de prestação de serviços e de inatividade, determinados em horas, dias ou meses, independentemente do tipo de atividade do empregado e do empregador, inclusive as disciplinadas por legislação específica. (NR)

Art. 477-A. As dispensas imotivadas individuais, plúrimas ou coletivas equiparam-se para todos os fins, não havendo necessidade de autorização prévia de entidade sindical ou de celebração de convenção coletiva ou acordo coletivo de trabalho para sua efetivação».

Antes da entrada em vigor da reforma trabalhista no Brasil, o trabalho em condições insalubres era completamente vedado às gestantes, com a nova redação do artigo 394-A, mediante a apresentação de atestado médico a gestante poderá continuar exercendo as suas atividades em trabalho com condições insalubres, desde que apresente atestado médico que garanta que o ambiente não afetará a saúde ou oferecerá algum risco à gestação ou à lactação, entretanto é possível questionar, se um atestado médico oferecerá a proteção mínima necessária à mulher e ao feto (Lei 13.467/2017).

\footnotetext{
${ }^{6}$ Lei 13.467/2017, que alterou a Consolidação das Leis Trabalhistas no Brasil (Decreto 5452/1943), aprovada no Senado em 13/07/2017.
} 
Acerca do artigo 442-B, antes da alteração legal, trabalhador autônomo era o pequeno empresário que organizava a sua rotina sem qualquer espécie de subordinação e sua atividade econômica era exercida em proveito próprio, os exemplos mais conhecidos desse tipo de trabalho são os profissionais liberais, médicos, dentistas, advogados, que atuavam com ampla liberdade e sem qualquer espécie de subordinação.

Ao incorporar a possibilidade de contratação no regime de trabalho autônomo a CLT flexionou proteções consolidadas ao trabalhador subordinado, ao contratar um trabalhador autônomo o empregador não assume nenhum risco em relação à atividade também não é compelido ao pagamento de nenhum dos direitos previstos na CLT, tais como férias $13^{\circ}$ salário, FGTS e os encargos com o INSS ficam a cargo do trabalhador (Lei 13.467/2017).

Com relação ao trabalho intermitente, cujo conceito é apresentado a partir da reforma trabalhista no artigo 443 e em seu $\S 3^{\circ}$, a conceituação legal para trabalho intermitente apresentou a ideia de que o contrato de trabalho (gerado pelo vinculo de emprego e com as incidências das regras da CLT) poderá ocorrer de forma alternada, ou seja, o trabalhador poderá se ativar em um período e permanecer sem atividade em outro período. Sendo que os períodos de intermitência serão fixados por horas, dias ou meses. Qualquer profissão ou atividade econômica poderá adotar o trabalho na forma intermitente, exceto os aeronautas. Inclusive o trabalho intermitente poderá ser conjugado com o trabalho por prazo indeterminado ou determinado, ou melhor, o contrato poderá ser indeterminado-intermitente ou determinado-intermitente (Lei 13.467/2017).

Os conceitos legais aproximam o trabalhador intermitente ao trabalhador avulso, ou seja, aquele que por intermédio de um Órgão Gestor de Mão de Obra ou Sindicato prestava serviços e só recebia pelos serviços prestados e ao final dos serviços de forma imediata. Porém, a significativa distinção é que neste (contrato intermitente) não há um terceiro gerindo o contrato do trabalhador, a relação é direta entre ele (operário) e empregador (Lei 13.467/2017).

O conceito é moderno e implica diversas reflexões e modificações na estrutura da prestação de serviços. Entretanto, essa forma de precarização deixa inúmeros questionamentos acerca da sua aplicação, uma vez que a Lei não esclarece, qual a periodicidade de pagamento para o caso de o contrato de trabalho perdurar por prazo superior a um mês - se o pagamento deverá ocorrer de forma mensal, semanal, diária ou por hora trabalhada.

A legislação não demonstra de forma clara se há algum limite de permanência do trabalhador na condição de intermitência, e se há um limite de tempo para manutenção do contrato com o trabalhador paralisado - e, portanto, em período em que não efetuará o seu trabalho e não receberá por isso.

Da mesma forma, o artigo 790 da CLT, foi alterado de forma prejudicial ao trabalhador, o texto legal incorporou disposições que claramente constituem um limitador ao acesso do trabalhador ao judiciário:

«Art. 790. (...)

$\S 3^{\circ}$ É facultado aos juízes, órgãos julgadores e presidentes dos tribunais do trabalho de qualquer instância conceder, a requerimento ou de ofício, o benefício da justiça gratuita, inclusive quanto a traslados e instrumentos, àqueles que perceberem salário igual ou inferior a $40 \%$ (quarenta por cento) do limite máximo dos benefícios do Regime Geral de Previdência Social.

$\S 4$ ㅇ O benefício da justiça gratuita será concedido à parte que comprovar insuficiência de recursos para o pagamento das custas do processo." 
“Art. 790-B. A responsabilidade pelo pagamento dos honorários periciais é da parte sucumbente na pretensão objeto da perícia, ainda que beneficiária da justiça gratuita. $\S$ 1o Ao fixar o valor dos honorários periciais, o juízo deverá respeitar o limite máximo estabelecido pelo Conselho Superior da Justiça do Trabalho.

$\S 2^{\mathrm{o}}$ O juízo poderá deferir parcelamento dos honorários periciais.

§ 3o O juízo não poderá exigir adiantamento de valores para realização de perícias.

$\S 4^{\circ}$ Somente no caso em que o beneficiário da justiça gratuita não tenha obtido em juízo créditos capazes de suportar a despesa referida no caput, ainda que em outro processo, a União responderá pelo encargo».

Ao dispor que o reclamante, para obtenção do benefício da justiça gratuita, deverá receber salário igual ou inferior a 40\% (quarenta por cento) do limite máximo dos benefícios do Regime Geral de Previdência Social e que deverá ainda, comprovar insuficiência de recursos para o pagamento das custas do processo, certamente a legislação acaba por fixar critérios que fatalmente excluirão a possibilidade de o empregado ver a sua demanda apreciada pelo poder judiciário.

Outro importante limitador de acesso ao judiciário imposto pela nova norma trabalhista, reside na questão relativa ao pagamento de honorários periciais, uma vez que o empregado mesmo detentor de Assistência Judiciária Gratuita, poderá ser impelido a arcar com as custas de honorários periciais, em caso de sucumbência, uma vez que mesmo o trabalhador não tendo obtido sucesso na demanda, se houver recursos a serem recebidos, ainda que em outra ação interposta, esses recursos serão utilizados para o pagamento do débito pericial. (Lei 13.467/2017)

As alterações trazidas pela Lei $13.467 / 2017$ aos artigos supra referidos colidem frontalmente com os princípios do Plano Nacional de Trabalho Decente ao autorizar o trabalho de gestantes em condições insalubres, a contratação indiscriminada de autônomos, o trabalho intermitente e as dispensas imotivadas plúrimas - sem necessidade de prévia autorização de entidade sindical ou de acordo coletivo. Considerando que a adoção dessas medidas efetua ampla restrição à proteção social do trabalhador e que na prática, o que está sendo relegado é o princípio da proteção ao trabalhador ${ }^{7}$, desrespeitando ainda os princípios e direitos fundamentais do trabalho, a promoção do emprego de qualidade e o fortalecimento do diálogo social.

A noção de trabalho decente integra as dimensões qualitativa e quantitativa do trabalho, propondo medidas direcionadas à geração de novos postos de trabalho e ao enfrentamento do desemprego e também, medidas que visem debelar formas de trabalho que gerem renda insuficiente para que os indivíduos atinjam condições mínimas aptas a superar as condições de pobreza visando assim, o combate à reprodução de situações de desigualdade social.

A Organização Internacional do Trabalho possui limitações na aplicação e ratificação de suas orientações e determinações, adotando uma técnica de governança denominada soft $l a w^{8}$, uma vez que não há força vinculante em suas convenções, tendo em vista que a ratificação destas pelos Estados-Membros não é mandatória, a Organização precisa atuar de

\footnotetext{
${ }^{7}$ Cf. Zenni \& Oliveira, 2009: 11 e segs. Como declinações do princípio de proteção os autores arrolam os princípios da condição mais benéfica, da norma mais favorável, do in dubio pro operário, da primazia da realidade, da continuidade da relação de emprego, da irrenunciabilidade, da intangibilidade salarial, da solidariedade do grupo econômico, da função social do contrato e da boa-fé.

${ }^{8}$ As normas de soft law são oriundas do direito programatório, que consubstanciam diretrizes gerais, em tese desprovidas de coercitividade, uma vez que não há meios jurídicos que possibilitem exigir que uma parte contratante cumpra com o que foi por ela pactuado com as demais (Mazzuoli, 2012: 185).
} 
forma ativa e ampla, no intuito de aumentar a adesão por parte dos Estados-Membros no cumprimento das Convenções (ILO, 2010, PNTD).

A principal estratégia da OIT para o tratamento da questão, visando estender a aderência aos seus padrões de trabalho tem um caráter reflexivo, que encontra amparo na teoria Luhmaniana: «O direito opera na sociedade, nela se executa, desempenha uma função social e se faz diferenciado para satisfazer a essa função por sua reprodução autopoiética própria» (Luhmann, 2016: 741).

Conforme Luhmann, o direito não é imutável, não se estabiliza no tempo, sob esta afirmação e sob um olhar que deriva da evolução social, é possível verificar que a noção de justiça se altera em conjunto com a sociedade na qual está estabelecida, seja em questões temporais, seja em questões culturais. Mas que independentemente das modificações, se faz necessário um imperativo comum para manutenção da ordem, é sob essa premissa que se dá a compreensão de que as normas de caráter transnacional encontram amparo na sociedade.

\section{Conclusão}

A percepção do desenvolvimento dos direitos do trabalho no âmbito transnacional, utilizando-se da Agenda do Trabalho Decente da Organização Internacional do Trabalho em conjunto com o Plano Nacional de Trabalho Decente viabilizou uma avaliação da atuação reflexiva da OIT.

Os pontos críticos apontados na reforma trabalhista realizada no Brasil indicam uma postura contrastante em relação às recomendações da Organização Internacional do Trabalho, uma vez que, enquanto o posicionamento da OIT - apesar da dificuldade na aplicação das Convenções e recomendações - é no sentido de adotar uma postura protetiva ao trabalhador, a reforma trabalhista, por sua vez, encarrega-se de reduzir a proteção social ao mínimo possível.

Embora o processo de governança global seja uma evolução das normas mundiais de convivência social, o deslocamento da atividade econômica de um país a outro nas décadas de 30 e 40, contribuiu para que emergisse uma nova divisão do trabalho, a América Latina sofreu impactos nesse processo, que não propiciou a redução de desigualdades que seguem sendo perpetradas por décadas.

Inicialmente tendo sido apontada como uma solução, a redução das proteções sociais ao trabalhador vem resultando somente em agravamento de situações empregatícias em caráter de precariedade extrema, reforçando os quadros de desigualdade social, é a partir desse cenário que se vislumbra a necessidade de ampliação do campo de atuação da Organização Internacional do Trabalho, visando o cumprimento de diversas orientações no sentido de proteger o trabalhador.

Assim, há a constatação de que a governança assume um papel multinível, que não se restringe aos governos de cada país, ampliando o campo de atuação para outras esferas de cooperação como organizações não governamentais e demais atores não estatais, transformando o Estado de forma significativa, sendo o processo de governança, parte da evolução na forma como se estabelece a convivência na esfera global.

É a partir dessa visão, que se estabeleceram os quatro principais objetivos da ANTD impulsionar o desenvolvimento sustentável e a inclusão social através da promoção do trabalho decente; a geração de mais e melhores empregos, com igualdade de oportunidades e de tratamento; a erradicação do trabalho escravo e do trabalho infantil, em suas piores formas; e o fortalecimento dos atores tripartites e do diálogo social como um instrumento de governabilidade democrática. 
Ainda que sejam relevantes as limitações na aplicação e ratificação de orientações e determinações da OIT, a adoção da soft law, ao imprimir ao processo um caráter de cunho reflexivo, eleva os debates a um outro patamar, mesmo que a Organização precise atuar de forma ativa e ampla, no intuito de aumentar a adesão objetivando o cumprimento de Convenções.

Apesar do proeminente papel da Organização Internacional do Trabalho, constata-se que as críticas à sua atuação giram principalmente com relação às questões relativas à representatividade, tendo em vista que a atuação da Organização se opera em um nível de distanciamento - tornando-a praticamente inalcançável ao cidadão comum - e também com relação à sua atuação junto aos países em desenvolvimento, nesse caso a crítica versa sobre a privação de vantagem competitiva com a adoção das recomendações. Entretanto em que pese essas considerações, o papel perante o cenário internacional, possui uma influência que não se pode desprezar.

O programa de Trabalho Decente usa a soft law como principal técnica de governança, a sua implantação imprime ao Direito do Trabalho uma tendência reflexiva, a partir da qual os Estados-Membros são incentivados a se utilizarem desse mecanismo com a finalidade de instalar os Programas Nacionais de Trabalho Decente - PNDT. A OIT fornece o suporte viabilizar a efetivação desses programas e ainda à coleta de dados, sobre o mercado de trabalho, análises econômicas e de indicadores com o objetivo de que as demandas do mercado de trabalho em emergência sejam respondidas. ${ }^{9}$

Por fim, é com o objetivo de aumentar a efetividade dos padrões de trabalho que a abordagem dentro de uma estratégia reflexiva se fortalece como tendência. A necessidade de refletir acerca de suas limitações desemboca na criação de novas estratégias criativas, admitindo os problemas decorrentes da ratificação pelos Estados-Membros. Na busca pela tomada de consciência sobre os seus padrões de trabalho, a OIT optou por priorizar, progressivamente, padrões específicos.

Essa priorização, visando o fortalecimento de padrões de trabalho, se operou a partir da identificação da conjuntura da sociedade mundial, o que ocorreu com o estabelecimento de uma Comissão Mundial da Dimensão Social da Globalização ${ }^{10}$.

Essa comissão originou um relatório indicativo dos principais padrões de trabalho. $\mathrm{O}$ documento constitui uma refutação às críticas procedentes dos países em desenvolvimento de que os padrões de trabalho os embargam de qualquer eventual vantagem competitiva, no cenário de uma economia global. Entretanto o relatório da comissão apontou o risco de uma flexibilização que gere um relaxamento nos padrões de Direito do Trabalho no mundo.

É sob esse aspecto que é possível concluir que a Reforma Trabalhista implementada no Brasil, partindo de uma política neoliberal que visa somente à redução de custos na contratação de trabalhadores, na verdade vem contribuindo com um retrocesso na capacidade de o Estado brasileiro enfrentar os principais problemas estruturais relativos ao mercado de trabalho, de forma sistemática, se opera a mudança de condições de emprego e trabalho decente, com amparo ao trabalhador, para situação endêmica e crescente de desemprego ou de trabalho precarizado, nesse cenário o país deixa de atender às recomendações da ANDT e da OIT, para ceder às pressões do mercado, sob o argumento de falta de competitividade das grandes empresas.

\footnotetext{
${ }^{9}$ ILO. Informe Mundial sobre la Protección Social 2017-2019 La protección social universal para alcanzar los Objetivos de Desarrollo Sostenible. 2017.

${ }^{10}$ Comissão Mundial Sobre a Dimensão Social da Globalização. Relatório - Por uma globalização justa: criar oportunidades para todos. ILO, 2005.
} 
O Estado por sua vez, ao atender aos anseios dos empregadores, a partir da implementação da referida reforma trabalhista, desampara ao trabalhador, permitindo um agravamento da desigualdade social existente, com a redução da cobertura de proteção social, o que tende a aumentar a parcela de trabalhadores sujeitos a salários baixos e elevados índices de rotatividade no emprego - pois uma vez que a mão de obra é barata e há poucos encargos envolvidos no processo de admissão e demissão de trabalhadores, os níveis de tolerância do empregador a qualquer atitude do empregado que porventura o desagrade, tendem a cair além disso, as condições de segurança e saúde nos locais de trabalho terminam por não serem observadas, considerando que há o amparo estatal para flexibilização das normas.

É relevante a promoção das normas internacionais do trabalho, principalmente no tocante a questão relativa à melhoria das condições de trabalho, com o indicativo de necessidade de ampliação da proteção social, sob o risco de não o fazendo, o país propiciar o agravamento de situações que envolvam trabalho infantil, trabalhos forçados, dentre outras formas degradantes.

\section{Referências}

Abramo, Laís (2015). Uma década de promoção do trabalho decente no Brasil: uma estratégia de ação baseada no diálogo social. Organização Internacional do Trabalho Genebra: OIT.

Bichara, Julimar. Conheça o Modelo Trabalhista Alemão - http://br.rfi.fr/geral/20150713conheca-o-modelo-trabalhista-alemao-que-inspirou-o-brasil-contra-o-desemprego. Acesso em: 02/05/2018.

Bull, H. (2002). A Sociedade Anárquica. Brasília: Ed. Universidade de Brasília.

Cesar, Alexandre (2002). Acesso à Justiça e Cidadania . Cuiabá: EduFMT.

De Miranda, J. A. \& W. Capeller (2018). «Sociedade, Direito e Política: uma analise do panorama atual da governança». Argumenta Journal Law, n. 27. Disponível em: Goo.Gl/CGTZLR.

De Miranda, J. A \& M. Frafa (2017). «Globalização a América Latina: impactos nos movimentos sociais, no Estado e no Direito na busca por mais igualdade». Prima Facie, V. 16, n. 31. P. 1-27, 2017. Disponível em: goo.gl/42woiP.

De Miranda, J. A. \& S. Cademartori (2018). «Governança Global e Sociedade Internacional: mais problemas comuns que interesses nacionais». Juris Poiesis, V. 21, N.25, p. 1-20 2018. Disponível em: goo.gl/oZksBD.

Devin, Guillaume (2009). Sociologia da Relações Internacionais. Salvador, Edufal.

Gaskarth, Glin (2014). «The Hartz Reforms - And their lessons for U.K.». Centre for PolicyStudies. Disponível em goo.gl/FTFUYR.

González, Ismael Camargo (2013). Derecho Constitucional Social y reconocimiento de los derechos de las minorías. Biblioteca Jurídica Virtual del Instituto de Investigaciones Jurídica de la UNAM. Universidad Nacional Autónoma de México, Instituto de Investigaciones Jurídicas. Disponível em: http://biblio.juridicas.unam.mx.

Goncalves, Alcindo; Costa Fontoura, J. A. (2011). Governança Global e Regimes Internacionais. São Paulo: Almedina.

Luhmann, Niklas (2016). O direito da sociedade. Tradução de Saulo Krieger e Alexandre Agnolon. São Paulo: Martins Fontes.

- El derecho de la sociedade (2006). Espanha: Herder.

- Introdução à teoria dos sistemas (2010). Tradução de Ana Cristina Arantes Nasser. 2. Ed. Rio de Janeiro: Vozes. 
Mazzuoli, Valério de Oliveira (2012). Direito Internacional Público - Parte Geral. 6. ed. São Paulo: Revista dos Tribunais.

Muldoon, Jr. James P. (2007). The New New Diplomacy: The Changing Character of Multilateral Diplomacy at the United States, British International Studies Association, University of Cambridge, UK, $2007 . \quad$ Disponível em: www.bisa.ac.uk/2007/pps/muldoon.pdf.

Nalini, José Renato (1997). Direitos Humanos: Novas perspectivas no Acesso à Justiça. Revista CEJ, n.03, São Paulo, dezembro de 1997. Disponível em: goo.gl/Sn2Szq.

Rocha, Leonel Severo; Germano Schwartz \& Jean Clam (2013). Introdução à Teoria do Sistema Autopoiético do Direito. Porto Alegre: Livraria do Advogado Ed.

Rosenau, J. \& E. Czempiel (2000). Governança sem Governo: ordem e transformação na política mundial. Brasília: Imprensa Oficial.

Salas, Carlos \& Rigoletto Tomás Pernías. Experiências Internacionais em Reforma Trabalhista - Centro de Estudos Sindicais e de Economia do Trabalho - UNICAMP Goo.Gl/Yrmvno.

Zenni, Alessandro Severino Valler \& Cláudio Rogério Teodoro de Oliveira. (2009). (Re)Significação dos princípios de Direito do Trabalho. Porto Alegre: Sérgio Antônio Fabris Editor.

Vieira, Liszt (1997). Cidadania e globalização. Rio de Janeiro: Record.

\section{Documentos}

ILO (2005). Comissão Mundial Sobre a Dimensão Social da Globalização. Relatório - Por uma globalização justa: criar oportunidades para todos.

ILO. PNDT (2010). Plano Nacional do Trabalho Decente - Gerar Trabalho Decente para Combater a Pobreza e as Desigualdades Sociais. Ministério do Trabalho e Emprego. Brasília. Disponível em: «goo.gl/Xn7HdG».

ILO (2015). Cooperação Sul-Sul para a promoção do Trabalho Decente • «goo.g1/74aQoc».

ILO (2017). Informe Mundial sobre la Protección Social 2017-2019 La protección social universal para alcanzar los Objetivos de Desarrollo Sostenible. Genebra: OIT.

ILO (2018). Perspectivas Sociais e de Emprego no Mundo: Tendências 2018. «goo.gl/VjssgK».

IPEA (2010). Avanços na Agenda Nacional do Trabalho Decente - Observatório do Mercado de Trabalho Nacional. «goo.gl/9wKsnL». 